\title{
CULTURAS EM TRANSFORMAÇÃO os índios e a civilização
}

\author{
Clarice Cohn \\ Doutoranda do Departamento de Antropologia da USP, bolsista do CNPq
}

Resumo: A partir da experiência de um grupo indígena brasileiro, este artigo realiza uma reflexão sobre as transformações culturais e o perigo de perda cultural e de identidade. Para isso, retomam-se os conceitos de cultura e civilização tais como concebidos e pela antropologia e no senso comum, contrapondo-os às noções indígenas de cultura e tradição, com o objetivo de entender como elas lidam com a permanência e a mudança cultural.

Palavras-chave: cultura; etnicidade; índios no Brasil; identidade; história indígena.

Mas não vejo como a humanidade poderia viver sem diversidade interna.

Lévi-Strauss $^{1}$

$\mathrm{M}$ uito se comenta, e se lamenta, que os índios estão perdendo sua cultura. Um índio calçado e vestido com calça jeans, falando português, utilizando gravadores e vídeos ou morando em uma favela em São Paulo aparece aos olhos do público como menos índio. Eles deveriam seguir suas tradições, se diz. E nós deveríamos deixá-los em paz, devolvê-los ao isolamento, para que possam seguir seus caminhos.

É claro que devemos muito aos nossos índios, e precisamos deixá-los em paz. A questão é como fazer isso. Certamente não é devolvendo-os a um isolamento que nunca conheceram, pois nós somos apenas mais um dos outros povos com que cada povo indígena manteve contato ao longo da história, seja através de trocas amistosas, seja de forma bélica. Por outro lado, não somos "apenas" mais um povo; nossa tecnologia nos faz especialmente perigosos e, ao longo desses 500 anos, a história não tem sido fácil para os índios, que tiveram que lutar para sobreviver a epidemias, guerras, escravidão, aldeamentos e esforços de integração à população nacional - e foram poucos os que conseguiram. Como, então, sem isolá-los, mantendo-os em uma redoma de vidro, podemos contribuir para sua sobrevivência física e cultural?
A questão da sobrevivência física impõe iniciativas objetivas: atendimento médico; garantia de território; punições a práticas de genocídio. Já a sobrevivência cultural apresenta problemas de outro tipo, sendo que o primeiro é defini-la. Para tanto, propõe-se, nesse artigo, fazer uma reflexão do que se entende por "cultura" e "tradição" e, portanto, por sobrevivência cultural, contrapondo essas concepções aos modos como algumas etnias indígenas as entendem e utilizam, em especial os Xikrin, grupo Kayapó que vive no Pará.

\section{A IDÉIA DA CULTURA}

O conceito de cultura tem uma longa história e sua origem é anterior ao esforço da antropologia de estudar e compreender povos com costumes e modos de vida diferentes. Como mostra Elias (1990), cultura e civilização são conceitos que surgem na Europa e que, já de início, ganham significados diversos entre as várias populações nacionais nascentes. Grosso modo, porém, esses termos parecem conotar a unidade ocidental e as diferenças internas a ela: se civilização é um resultado final de um processo que culmina no Ocidente, cultura designa as particularidades das populações ocidentais - os modos franceses, ingleses, alemães.

$\mathrm{Na}$ antropologia evolucionista de fins do século XIX, uma história comum a todos os povos culminaria na civi- 
lização ocidental, ápice da evolução, e as diferenças culturais ficavam subordinadas a uma concepção de estágios, ou estados, que deveriam ser ultrapassados. Funda-se então a missão civilizatória ocidental. Com a crítica aos evolucionistas e a admissão da relatividade cultural, a antropologia norte-americana, de um lado, e a inglesa, de outro, recusam o que foi chamado de pseudo-história ou história conjectural e buscam entender a diferença cultural. Está em jogo, aqui, uma oposição entre diferença e desigualdade.

$\mathrm{Na}$ antropologia americana, cultura passa a ser definida como um conjunto de traços que podem ser perdidos ou tomados de empréstimo de populações vizinhas, enquanto a antropologia britânica a pensa como um sistema de partes articuladas entre si, cuja lógica própria deve ser entendida. Porém, essa visão de "traços culturais" que podem ser perdidos acaba por levar à noção de aculturação, ou seja, de um processo regressivo de perda cultural, a que os povos nativos (não-ocidentais, "primitivos") de todo o mundo estariam especialmente sujeitos. Passa-se, então, a se preocupar com o desaparecimento da diversidade cultural.

As discussões a respeito da etnicidade reviram essa definição reificadora da cultura, como traços ou elementos que podem ser perdidos, e focaram as fronteiras que delimitam uma cultura (Barth, 1969). Nessa acepção, o que define uma cultura não são seus traços constitutivos, mas sim o estabelecimento da fronteira entre um e outro, o que é feito pela atribuição da diferença, pelos traços diacríticos (Carneiro da Cunha, 1986). Assim, o que importa não é a manutenção dos traços em si, mas da diferença que origina a identidade e que é estabelecida contextualmente por meio de traços maleáveis e flexíveis. A cultura não deve se manter em uma suposta integridade; o que deve ser preservada é sua diferenciação em relação às outras, são as fronteiras, e essas são traçadas por elementos que têm origem cultural, mas são escolhidos em contexto.

Mais do que isso, as culturas foram percebidas em suas transformações. Todas as culturas estão na história, o que diverge entre elas é o modo como lidam com a história com que se defrontam e se transformam (Sahlins, 1991). Portanto, a mudança cultural deixa de ser percebida como um fantasma que assombra os nativos do mundo todo e passa a ser entendida como um meio de reprodução social que é pautada também pela história.

A figura do índio no Brasil e o espaço que ele ocupa na sociedade brasileira têm sido concebidos também de modo mutante. Em um primeiro momento, pensa-se o índio como parte da formação da sociedade brasileira, tratando-o, como importante, no passado, para a constitui- ção da singularidade nacional; o foco está, assim, no índio como nosso antepassado, nas heranças que deles recebemos, seja genética, seja cultural, seja na importância que ele teve para a adaptação do colonizador europeu ao novo meio. ${ }^{2}$ Esse foco tem suas raízes na teoria de Freyre, mas foi Darcy Ribeiro quem primeiro elegeu o índio como o principal personagem de sua teoria sobre o Brasil.

Sendo, não por acaso, Darcy Ribeiro também um indigenista ligado ao SPI (Serviço de Proteção ao Índio, o poder tutelar à época, posteriormente substituído pela atual Funai), seus trabalhos mostravam a preocupação com o destino das populações indígenas, com sua aculturação e integração à sociedade nacional. Baseada em uma teoria que considerava a cultura composta por traços que poderiam ser perdidos, essa corrente denunciava e buscava investigar a assimilação do índio e sua transformação em trabalhador rural, no "índio destribalizado", no dizer de Ribeiro, que seria reduzido à massa disforme de campesinato.

O conceito de fricção interétnica, cunhado e utilizado por Roberto Cardoso de Oliveira (1962 e 1964), começou a problematizar essas assunções, mas foi a geração seguinte que partiu da idéia de que as culturas indígenas não se perdem e que as sociedades indígenas atuam sempre na re-constituição de uma identidade diferenciada. De fato, essa percepção foi possibilitada, ou enfatizada, por mudanças históricas recentes, especialmente os novos direitos estabelecidos pela Constituição de 1988 - entre eles, os direitos a terras e à diferença cultural (Marés, 1992)-, pelo grande crescimento populacional indígena comprovado pelas estatísticas, que inclui também a emergência de etnias tidas como desaparecidas, e, finalmente pelo fortalecimento do movimento indígena, que cria uma identidade comum, de "índios" (em contraposição aos "brancos" e negros) aos diversos grupos etnicamente diferenciados (Ricardo, 1995). A idéia da "sociodiversidade nativa" fala de uma nova valorização do índio como parte integrante da nação em sua especificidade, sendo que o reaparecimento de grupos tidos como extintos e assimilados leva à percepção de mecanismos de re-construção de identidade étnica por eles engendrados.

\section{TRADIÇÃO CULTURAL}

A percepção das dinâmicas sociais e culturais exige que se atente não apenas às tradições, como também à inovação; não se nega, assim, a reprodução social, mas ampliase a noção de reprodução social, de modo que inclua a possibilidade de mudança. Desse modo, vai-se além da 
proposição de que estas sociedades têm, em todos os seus aspectos, como objetivo único a perpetuação estanque. Vários antropólogos têm se dedicado à reflexão de como essas modificações se efetuam e efetivam. Como demonstração e ilustração dessa mudança permanente das tradições culturais, citam-se dois exemplos retirados de análises antropológicas de realidades bastante diversas: a região das Guianas e a Nova Guiné.

No primeiro caso, discute-se o uso social da história para a criação e reprodução da identidade entre os Saramaka do Suriname, sociedade constituída por escravos fugidos. Richard Price aborda o aprendizado sobre o "passado significante", o First Time, que se refere aos antepassados à época de origem da sociedade, fonte da identidade coletiva. Se há nos Saramaka o que Price chama de uma "clara opção cultural" pela ênfase nas situações específicas, formais, de transmissão como fonte do conhecimento, existe, no entanto, uma ênfase em outro sentido, o da fragmentação deliberada dessa transmissão, baseada na expectativa de que cada homem adulto forme seu próprio conhecimento sobre o First Time ao longo da vida. Assim, a transmissão deste conhecimento não se limita a uma fonte única, mas é concebida como um processo que se inicia, para cada indivíduo, com o relato fragmentário ${ }^{3}$ por um parente mais velho, tendo continuidade ao longo de sua vida, agora desvinculada de um parente e de uma situação formal. Tratando-se de um conhecimento essencial para fornecer sentido ao presente, o autor demonstra que a fragmentação na transmissão pode ser uma estratégia para reprodução e permanência desse saber, gerando conhecimentos muito individualizados.

Estudando em outra região do globo, Frederik Barth recusa a noção de que a cultura é um todo homogêneo e compartilhado, ao analisar as variações locais da tradição cosmológica das Montanhas Ok da Nova Guiné. Estas variações são explicadas através da análise da situação específica em que ocorrem, ou seja, da realização, regular mas com longos intervalos e em templos espacialmente dispersos, de rituais de iniciação. Relacionados a uma cosmologia que deve ser mantida em segredo e comunicada apenas em ocasiões especiais, cuja simbologia é construída por analogias e metáforas (o que gera ambigüidade de significados, além de um leque de significados possíveis), os conhecimentos necessários para a realização dos rituais são armazenados por um restrito número de pessoas durante esses intervalos.

Essas poucas pessoas constituem-se em guardiões, em nome da comunidade, desse conhecimento que é valori- zado socialmente, e a cada novo ritual são responsáveis por sua recriação; trata-se de indivíduos que têm autoridade para fazer modificações no seio da tradição a cada nova realização do ritual. Barth enfatiza que a concepção nativa é a de que cada ritual é feito a partir das rememorações dos anteriores por esses indivíduos. $\mathrm{O}$ autor reconhece na complementaridade dos processos de subjetivação (durante o intervalo de realização dos rituais) e de reobjetivação (a cada nova realização) a emergência da criatividade individual que, ao se acumular no tempo, gera as variações que podem ser observadas em cada "subtradição". Essa recriação individual, porém, não deve ser levada ao pé da letra, pois toda representação individual refere-se à simbologia coletiva e, portanto, a cosmologia Ok só pode ser entendida como sendo produzida e reproduzida através de processos que são sociais e coletivos.

Se Price apresenta uma situação em que a reprodução social pressupõe a fragmentação na transmissão da tradição, Barth sugere que a homogeneização gerada por cada ritual de iniciação é apenas parte de um processo, que tem sua continuidade no alargamento que cada indivíduo pode realizar, ou não, do conhecimento adquirido naquele momento. Portanto, não se pode supor que a cultura é um todo compartilhado e o que se transmite através das gerações não se constitui em totalidades. A tradição não é um corpus fechado que persiste no tempo. O processo de transmissão de uma tradição diz respeito a uma reprodução social que convive com a mudança, a variação inerente ao ato de repetição (Detienne, 1985:53-4). Como lembra Jack Goody (1987:X), em sociedades orais, o que é falado continua mais que perdura.

\section{OS XIKRIN E AS TRANSFORMAÇÕES CULTURAIS}

Ao lado de uma prática própria de transmissão de conhecimentos, os Xikrin têm uma noção diversa da nossa do que vem a ser transmissão, aprendizado e conhecimento. Do mesmo modo, o significado, para eles, de tradição e de sua cultura encontra uma formulação cultural específica. A discussão, nesse item, baseia-se em pesquisa sobre infância e aprendizado entre os Xikrin do Bacajá, ${ }^{4}$ além de informações fornecidas por outros estudiosos dos Kayapó, no sentido de verificar como eles entendem a permanência e a mudança cultural.

Para os Xikrin, o aprendizado é realizado por meio do olho e do ouvido, ambos órgãos que devem ser desenvolvidos, fortalecidos, como dizem, nos indivíduos para que se 
tornem capazes de aprender. Enquanto estes órgãos estão ainda "fracos", nas crianças, permite-se uma livre observação de todas as esferas da sociabilidade, mas não se exige a plena compreensão. Quando são fortalecidos, na idade madura, as pessoas são consideradas capazes de aprender, devendo saber agir corretamente e deter conhecimentos.

$O$ aprendizado é referido por termos que designam tanto as habilidades de ver (omunh) e ouvir (mari), como de entender, compreender e saber. Se estas últimas habilidades estão contidas tanto na visão quanto na audição, esta última engloba a primeira, pois é condição necessária à compreensão: para os Xikrin, não basta ver algo para aprender a fazê-lo, mas deve-se efetivamente compreender o que está sendo feito, e isso se faz pelo ouvido, algo como prestar atenção, "parar para pensar". Portanto, não se distingue coisas que se aprende olhando e coisas que se aprende ouvindo, sendo que tudo, mesmo aquilo que se vê (a confecção de um objeto, por exemplo, não é ensinada verbalmente, nem mesmo por uma explicação verbal do que está sendo feito, mas é aprendida por uma observação respeitosamente silenciosa), deve ser entendido e compreendido, habilidade que se relaciona ao ouvido.

Esta habilidade pode ser posta em prática e acionada pelos indivíduos em qualquer momento. Isso quer dizer que qualquer evento apresenta uma possibilidade de aprendizado e os Xikrin não determinam situações e contextos específicos para isso. Não há, entre eles, situações formais de ensino e transmissão. Existem, certamente, algumas mais formalizadas, como nas falas em que os velhos exortam os jovens a agir do modo definido pela sociabilidade xikrin e relatam conhecimentos, e outras que se voltam especialmente aos jovens solteiros, que, até se casarem, moram na casa central onde se reúnem os homens, conformando um grupo coeso e definido. Porém, a ênfase cultural, para parafrasear Price, está na iniciativa pessoal e na prática de pedir (kukia) a alguém que reconhecidamente detenha um conhecimento para ensiná-lo. Esse pedido não é restrito a algumas esferas de relações sociais, exigindo-se apenas que o pedido seja endereçado de modo correto, o que às vezes determina que se recorra a um intermediário. ${ }^{5}$

Portanto, configura-se entre os Xikrin uma situação em que a distribuição dos conhecimentos não é determinada por regras formais de transmissão e por espaços e ocasiões de ensino, mas sim pela iniciativa dos indivíduos. Há pessoas reconhecidas por habilidades ou por deter conhecimentos específicos, mas essa qualidade não é transmissível; ao contrário, ela depende da disposição do outro de aprender e de sua iniciativa, seja apenas de "sentar ao lado", seja, mais de pedir que lhe seja ensinado. E o que será ensinado, nesses casos, jamais será uma totalidade cultural. Do mesmo modo, essa totalidade não necessita ser pressuposta para ser segmentada e distribuída socialmente, mas se faz e refaz a cada geração.

No entanto, os Xikrin preocupam-se muito com a perpetuação de sua cultura e com a continuidade de sua transmissão. Alguns conhecimentos devem ser aprendidos e passados adiante (iukre iaren, continuar a contar, no sentido de contar para a próxima geração), o que eles chamam de kukradjà.

As referências a esse conceito na literatura antropológica sobre os Kayapó e os Xikrin são muitas e sua variabilidade de interpretações mostra a abrangência do termo. Por exemplo, Lea (1986:64-5) o define como "um conceito abstrato, mas fundamental na língua Kayapó (...) tem conotações de singular ou de plural, e pode ser traduzido de várias maneiras, dependendo do contexto. Uma glosa possível seria 'uma parte do todo', ou 'as partes constitutivas da totalidade', seja esta um corpo orgânico (composto de cabeça, tronco e os membros) ou um corpus de conhecimento ou tradições".

A autora menciona, ainda, a tradução, feita por eles, como "cultura" e seu uso como designando a cultura Kayapó e remetendo à identidade desse grupo. Fisher (1991:313-15) estabelece também uma analogia entre esse termo e cultura, traduzindo-o por "pieces stuff", algo feito de partes. Em outro texto, afirma: "a qualidade de ser Kayapó, no entanto, não se liga ao que é fisicamente compartilhado, mas à posse, 'dentro da cabeça', de um conhecimento específico de tradições culturais. O mais autêntico desses conhecimentos (kukradjá) é centrado em códigos de conduta e em regras de saúde, abrangendo também conhecimento cerimonial, mitologia, etc." (Fisher, 1996:3-4, tradução de Clarice Cohn).

Embora Vidal (1977) não realize uma discussão do termo, oferece explicações em notas de rodapé quando os relatos míticos que reproduz em seu anexo o trazem. Assim, em um relato, traduz m-kukrodjà-tum como "os velhos que possuem o conhecimento que nos deram de presente" e kukradjà como "conhecimento; propriedade desse conhecimento" (Vidal, 1977:205, notas 1 e 3); em outro, kukradjà é traduzido como "um privilégio herdado de um ingêt (avô ou irmão da mãe)" (Vidal, 1977:231, nota 2). ${ }^{6}$ Existem, portanto, duas acepções para o termo: a referência a conhecimentos e à identidade étnica; e a denominação de prerrogativas rituais que têm uma regra definida de transmissão. Vejamos o uso que os Xikrin do Bacajá 
fazem desses termos e o que se pode aprender sobre suas expectativas de uma sobrevivência cultural.

Eles referem-se à sua identidade cultural como me kukradjà, em oposição aos não-kayapó, em geral, e aos brancos, em particular, que têm kuben nhõ kukradjà (não-kayapó/ possessivo/“cultura"). ${ }^{7}$ A cultura dos brancos engloba não só seus conhecimentos específicos, mas também suas produções: ${ }^{8}$ avião, roupa, miçangas, etc. Nesse contexto, me kukradjà se amplia para denotar tudo o que é específico de uma identidade étnica Kayapó. Me kukradjà tum ganha a conotação do que os Kayapó têm desde sempre, do que é dos antigos, e refere-se a mitos, música e a tudo o que é idealmente transmitido através das gerações. Para eles, kukradjà nomeia também os bens transmitidos por uma kwatwy ou um ngêt, sendo substituído, às vezes, por kukrex.

Kukradjà, portanto, define, para os Xikrin do Bacajá, tanto um conhecimento coletivo, compartilhado, como o que é segmentado por natureza, ou seja, as prerrogativas rituais, transmitidas individualmente. Seria, ainda, uma aproximação do que chamamos de "tradição cultural", ou seja, tudo o que deve ser transmitido pelas gerações (o que é enfatizado pela necessidade da continuidade da transmissão), mas também para além do que poderia ser caracterizado como traços culturais, diacríticos, o que lhes é específico, o que os diferencia dos outros grupos étnicos, em geral, e dos "brancos", em particular.

No entanto, nenhum desses aparentes conjuntos se constitui em totalidades prévias e fechadas. A passagem efetuada pelos Xikrin para a cultura se deu nos tempos míticos, no qual a aquisição de bens culturais pertencentes a esferas (atualmente) externas ao social permitiu a conformação do socius e das diferentes categorias que o constitui, apropriando-se do fogo que era da onça, ou os adornos plumários das penas de um gavião canibal. ${ }^{9}$ No entanto, o sistema social assim formado não é fechado; ao contrário, ele mantém uma abertura para o exterior que realimenta continuamente as diferenças (sejam voltadas para o exterior, de uma identidade coletiva - de humanidade e etnicidade -, sejam as internas, prerrogativas de certas categorias de pessoas) que o conformam, dando continuidade ao processo de sua interiorização iniciado nos tempos míticos.

As relações com outros seres que compõem o cosmos xikrin, sejam eles animais, sobrenaturais ou humanos-outros, permitem a incorporação contínua de elementos do exterior. ${ }^{10}$ Como os Kayapó-Mekrangoti apresentados por Verswijver (1992), os Xikrin sempre fizeram da guerra uma fonte de recursos simbólicos e/ou materiais. Fazendo a guerra com outras populações indígenas ou com os "brancos", apropriavam-se de sementes para diversificar suas roças, ornamentos, roupas, alimentos industrializados, cachorros para a caça. Raptavam também mulheres e crianças, que recebiam um marido ou pais adotivos na aldeia e ensinavam aos Xikrin seus cantos, danças, rituais. Utilizavam as roupas que pilhavam suas prerrogativas, transmitidas para seus tabdjuo, e as ostentavam com orgulho nos rituais - às vezes, bonés sujos e velhos ou camisas que parecem destoar do quadro formado pela população entretida nos rituais são preciosos bens simbólicos e, longe de serem a prova da desintegração social ou cultural, constituem, ao contrário, prova de sua vivacidade, de sua constituição contínua.

Hoje, oficialmente contactados pela Funai (desde a década de 50, em um longo processo de aproximação e distanciamento), os Xikrin foram, para utilizar o jargão oficial, "pacificados" e não fazem mais a guerra. Porém, seus contatos amistosos permanecem e aqueles com quem guerreavam tornaram-se, ao menos em certos contextos, "índios como nós". Assim, uma rede ampliada de trocas permite que os Xikrin dêem seguimento ao seu processo de apropriação de bens do exterior, em suas viagens para as cidades ou para outras aldeias, por intermédio das fitas de gravadores e de vídeos que registram rituais praticados por outros índios, ao receberem visitantes, e pelas suas relações, mais ou menos bem-sucedidas, com as diversas categorias de "brancos" com que se defrontam.

Portanto, assim como ao matar o gavião mitológico que lhes forneceu, pelas penas que lhes eram tiradas do corpo, os adornos plumários - preciosa prerrogativa ritual-, os Xikrin permanecem retirando do seu cosmos, agora ampliado por uma nova categoria de seres, os "brancos", elementos que são incorporados como conhecimentos, prerrogativas, kukradjà. Sua tradição permanece sendo remodelada, mutante, e sua identidade vai sendo redefinida por coisas que incorporam, dentre outros, de nós.

\section{CONCLUSÃO}

Os Xikrin não são os únicos a nos fazer rever os conceitos de tradição e sobrevivência cultural; pelo contrário, de um modo ou de outro, essa é uma realidade presente para todos os povos indígenas. Para dar apenas dois exemplos, citam-se os Xavante e os Waiãpi. Os primeiros são índios também de língua Jê, habitantes do cerrado, e atualmente envolvidos em parcerias as mais diversas: com biólogos e botânicos, colaborando para a formulação de planos de desenvolvimento sustentável que combinam os dois modos de 
conhecimento do que chamamos de natureza; com videastas e programadores, registrando rituais que são vistos por eles, mas principalmente utilizados na divulgação de "sua cultura" para os "brancos", e criando páginas na internet; gravando discos com a banda Sepultura; fazendo apresentações de rituais nas grandes cidades (Graham, 2001). Os Xavante têm conseguido ganhar visibilidade na mídia, a partir da combinação de uma ênfase na tradição e inovações na divulgação e na colaboração com profissionais das mais diversas áreas. Ou seja, a inovação na comunicação com o exterior e nas relações interétnicas é utilizada para mostrar sua indianidade por meio da divulgação de sua tradição e cultura mantidas ou melhor, divulgadas como mantidas, perpetuadas, em resposta à expectativa de imutabilidade que descobriram nos brancos.

Outra etnia indígena que permite repensar a perda cultural são os Waiãpi, povo tupi da Amazônia. Para eles, as noções de tradição cultural e civilização são articuladas nas relações entre grupos locais distintos. Os Waiãpi reencontram-se após quatro décadas separados pela fronteira nacional Brasil/Guiana Francesa, sem estabalecer contato. As políticas indigenistas distintas dos governos francês e brasileiro conformam as relações que cada um dos grupos locais Waiãpi estabelecem com as respectivas sociedades nacionais vivendo uma política integracionista, a fração guianense é percebida como "mais civilizada" e mais rica, por ser detentora de maior número de bens industrializados. Já os Waiãpi brasileiros, lutando por sua autodeterminação, são tidos como "guardiões da tradição". Desse modo, atualmente os Waiãpi se concebem como complementares e desiguais, uns como tendo perdido a cultura e se "civilizado", outros como a preservado. Nessa reformulação das diferenças, vantagens e desvantagens de ambas as condições se manifestam e a relação assimétrica que se impõe deve ser entendida como uma balança que ora pende para um lado, ora para outro: "tanto civilização como cultura figuravam nessa intriga intercomunitária como signos de prestígio, ora representados em seu aspecto material (bens), ora em seus aspectos imateriais (conhecimentos)" (Sztutman, 2000:243), grifos no original). Portanto, os encontros desses grupos locais colocam um jogo uma relação de troca com uma dupla assimetria. Uns, da Guiana Francesa, estão em vantagem na troca de bens valorizados, os provenientes da sociedade industrial, enquanto outros, os brasileiros, são percebidos como detentores da cultura que teria sido perdida pelos que se "civilizaram". ${ }^{11}$ Mais ricos ou mais pobres em bens materiais ou cultura, cada um dos grupos locais entra na troca inter- comunitária com um fator de prestígio, sendo que a assimetria inicial se anula. Esse jogo complexo faz deste caso um exemplo de como a preservação ou a "perda" cultural pode ser apropriada pelos índios e instituir uma nova modalidade de troca, ela mesma culturalmente determinada.

Poder-se-ia lembrar ainda da "explosão étnica" que se vivencia atualmente no Brasil. Populações e indivíduos que negavam sua identidade indígena, se vêem em um contexto modificado, em que ser índio não é mais uma vergonha ou mesmo um perigo, a partir principalmente da Constituição de 1988, e voltam a articular sua "indianidade". O que interessa aqui é o modo como essa articulação é feita, ou seja, recuperando-se, ou mesmo construindo-se, signos de identidade indígena reconhecidos pela sociedade nacional. Embora a identidade étnica esteja juridicamente definida a partir do conceito de auto-identificação e adscrição, essas populações se apercebem por meio da expectativa da população brasileira de que os índios pareçam índios e, assim, se pintam, fazem para si cocares (diante falta de penas de arara, com penas de aves criadas) e utilizam tangas. Apropriam-se, portanto, do estereótipo que nossa sociedade criou para os índios. ${ }^{12}$

Sahlins (1997b:26), comentando as estratégias recentes dos Kayapó-Gorotire a partir das análises de Terence Turner, ressalta: “Os Kayapó não recusam a história: eles se propõem a responder por ela; pretendem orquestrá-la segundo a lógica de seus próprios esquemas. (...) na luta contra o Leviatã moderno, a continuidade das culturas indigenas consiste nos modos específicos pelas quais elas se transformam" (grifos no original).

Para retomar a pergunta formulada no começo desse artigo, parece que resta apenas a saída de deixá-los em paz para seguirem seu próprio caminho, ou seja, assumilos como sujeitos de sua própria história, capazes de conduzir e negociar suas mudanças. Pode-se, isso sim, serem criadas melhores condições para que eles façam sua história, para o que a Consituição de 1988 contribui de modo valioso. Porém, não somos nós quem deve decidir qual a "cultura" que eles devem seguir, e muito menos como irão manter suas tradições. Afinal, parafraseando Goody, as culturas continuam mais que perduram.

\section{NOTAS}

1. In: Mito e significado. Lisboa, Edições 70, p.33-5.

2. Essa imagem do índio é forte no "senso comum". Para vê-lo, basta pesquisar livros didáticos sobre a história do Brasil, os quais, com algumas honrosas exce- 
ções, ainda apresentam o índio como parte de um passado e suas contribuições para a formação da nação.

3. No caso dos relatos, a fragmentação é determinada em grande parte pela atribuição de perigos sobre-humanos que podem ser gerados no momento do relato; o medo é, porém, balanceado pela necessidade de que o conhecimento não se perca, e o resultado é uma "narrativa parcial dirigida a parentes selecionados" (Price, 1983:22); a fragmentação do conhecimento e de sua transmissão é mais ampla, porém, e abrange a formação individual do corpus aprendido.

4. Os Xikrin são um subgrupo Kayapó e pertencem ao tronco lingüístico Jê. Eles se dividem em quatro aldeias, duas na reserva indígena do Cateté, no sul do Pará, e duas mais ao norte, no sudoeste do Pará, na Terra Indígena Trincheira-Bacajá, ambas à margem do Rio Bacajá, afluente do Xingu. A pesquisa, com financiamento da Fapesp e do CNPq, foi realizada na aldeia do Bacajá, cuja população é de cerca de 400 pessoas (Cohn, 2000).

5. Quando, por exemplo, há restrições sociais a que se fale com a pessoa. Cita-se o exemplo de um rapaz que desejava aprender algo que sabia ser dominado por um velho a quem chamava de "sogro" (era pai classificatório de sua mulher). Assim, pediu a um jovem com quem podia falar livremente e que, por sua vez, tinha liberdade de se dirigir ao velho, que fizesse o pedido e os acompanhasse à floresta para intermediar o ensino.

6. Refere-se às prerrogativas rituais, constituídas de cantos, danças, ornamentos rituais, participação em determinados rituais, que seguem uma regra de transmissão - das categorias de ngêt (avô ou tio materno, reais ou classificatórios) ou kwatwy (avó ou tia paterna, reais ou classificatórias) para o termo recíproco, tabdjuo. Ressalte-se, que essa linha de transmissão de prerrogativas não tem reflexos na transmissão formal de conhecimentos a elas referentes, e que os conhecimentos rituais são adquiridos quando se participa ou assiste um ritual. Em outros subgrupos Kayapó, as prerrogativas herdadas são denominadas nekrex (Lea, 1986; Turner, 1993); entre os Xikrin, este termo denomina, especificamente, alguns cocares, e kukradjà abrange também as prerrogativas individuais (Cohn, 2000).

7. Assim como a fala (língua), Kayapó é denominada me kaben, em oposição ao português, kuben kaben. Kaben refere-se à fala, e o termo kuben denota, contextualizadamente, os brancos ou índios de outras etnias (Cohn, 2001).

8. Note-se que o mito de Wak me kaprã, do qual se pode encontrar uma versão em Vidal (1977:265), narra como um ancestral sabia fazer aviões, miçangas, armas de fogo, etc., e acaba por se tornar branco; ver também Gordon (no prelo).

9. Para o debate sobre as relações com o exterior estabelecidas pelas sociedades indígenas e sua determinação do socius, ver Overing (1983-1984), Menget (1985) e Viveiros de Castro (1993).

10. Para uma análise do cosmos xikrin e da criação dos adornos plumários, ver Giannini (1991).

11. É interessante notar, ainda, que os grupos locais da Guiana Francesa, tidos como os que se civilizaram, são simultaneamente concebidos como tendo mantido o xamanismo (Sztutman, 2000:229-231).

12. Isso pode ser visto muito claramente nas recuperações étnicas dos índios do Nordeste; ver Oliveira Filho (1999). Sahlins (1997a, 1997b) denomina essa estratégia de "culturalismo". Por ela, os índios reificam a cultura, invertendo o percurso da disciplina antropológica: quando esta percebe que as culturas não são traços objetiváveis, mas estão em constante mutação, mesmo que estruturalmente dirigida, eles se apropriam de traços tidos como indígenas para seu reconhecimento étnico.

\section{REFERÊNCIAS BIBLIOGRÁFICAS}

BARTH, F. Ethnic groups and boundaries. The social organization of culture difference. Boston, Little, Brown and Company, 1969.

Cosmologies in the making: a generative approach to cultural variation in inner New Guinea. Cambridge, Cambridge University Press, 1987.

CARDOSO DE OLIVEIRA, R. "Estudo de áreas de fricção interétnica no Brasil". América Latina, ano V, n.3, 1962. Livro, 1964

O índio e o mundo dos brancos. São Paulo, Difusão Européia do

CARNEIRO DA CUNHA, M. "Etnicidade: da cultura residual mas irredutível". Antropologia do Brasil. São Paulo, Brasiliense/Edusp, 1986.

COHN, C. A criança indigena: a concepção Xikrin de infância e aprendizado. Dissertação de Mestrado. São Paulo, Universidade de São Paulo, 2000.

"Índios missionários: cultos protestantes entre os Xikrin do Bacajá". Revista Campos 1. Curitiba, UFPR, Departamento de Antropologia, 2001.
"A experiência da infância e o aprendizado entre os Xikrin". In: LOPES DA SILVA, A. e PEREIRA, N. (orgs.). Antropologia da criança. São Paulo, Global/Mari, no prelo.

DETIENNE, M. "Por la boca y por el oído". La invención de la mitologia. Barcelona, Ediciones Peninsula, 1985

ELIAS, N. O processo civilizador. Rio de Janeiro, v.1, Jorge Zahar Editor, 1990.

FISHER, W.H. Dualism and its Discontents: social organization and village fissioning among the Xikrin-Kayapo of Central Brazil. Dissertation to the Faculty of the Graduate School of Cornell University, 1991, mimeo.

. "Kayapo leaders, public associations, and the ethnophysiology of age and gender", paper apresentado ao simpósio "Amazonia and Melanesia: Gender and Anthropological Comparison", 1996, mimeo.

GRAHAM, L.R. "Os Xavante na cena pública”. In: RICARDO, C.A. (org.). Povos indígenas no Brasil, 1996-2000. São Paulo, Instituto Socioambiental, 2000.

GIANNINI, I.V. A ave resgatada: "a impossibilidade da leveza do ser". Dissertação de Mestrado. São Paulo, Universidade de São Paulo, 1991.

GOODY, J. "Prefácio”. In: BARTH, F. Cosmologies in the making: a generative approach to cultural variation in inner New Guinea. Cambridge, Cambridge University Press, 1987.

GORDON, C. "Nossas utopias não são as deles: os Mebengokre (Kayapó) e o mundo dos brancos". Sexta-Feira. Antropologia, Arte, Humanidade, n.6, no prelo.

LEA, V. Nomes e Nekrets Kayapó: uma concepção de riqueza. Tese de Doutorado. Museu Nacional - UFRJ, 1986, mimeo.

MARÉS, C.F. "O direito envergonhado: o direito e os índios no Brasil". In: GRUPIONI, L.D.B. (org.). Índios no Brasil. São Paulo, SMC, 1992.

MENGET, P. "Présentation" e "Jalons pour une étude comparative". In: MENGET, P. (org.). Guerre, societés et vision du monde dans les basses terres de l'Amérique du Sud. Journal de la Societé des Americanistes, LXXI, 1985.

OLIVEIRA FILHO, J.P. de (org.). A viagem da volta. Etnicidade, politica e reelaboração cultural no Nordeste indígena. Rio de Janeiro, Contra Capa, 1999.

OVERING, J. "Elementary structures os reciprocity: a comparative note on Guianese, Central Brazilian, and North-West Amazon socio-political thought". Antropologica, 59-62, 1983-1984.

PRICE, R. First time: the historical vision of an afro-american people. The John Hopkins University Press, 1983.

RIBEIRO, D. Os indios e a civilização: a integração das populações indígenas no Brasil moderno. Petrópolis, Vozes, 1977.

RICARDO, C.A. "Os índios e a sociodiversidade nativa contemporânea no Brasil”. In: LOPES DA SILVA, A. e GRUPIONI, L.D.B. (orgs.). A temática indígena na escola. Brasília, MEC/Mari/Unesco, 1995.

SAHLINS, M. Ilhas de História. Rio de Janeiro, Zahar, 1991.

. "O 'pessimismo sentimental' e a experiência etnográfica: porque a cultura não é um 'objeto' em via de extinção (parte I)". Mana - Estudos de Antropologia Social, Museu Nacional. Rio de Janeiro, v.3, n.1, UFRJ, $1997 \mathrm{a}$.

. "O 'pessimismo sentimental' e a experiência etnográfica: porque a cultura não é um 'objeto' em via de extinção (parte II)". Mana - Estudos de Antropologia Social, Museu Nacional. Rio de Janeiro, v.3, n.2, UFRJ, 1997b.

SZTUTMAN, R. Caxiri, a celebração da alteridade: ritual e comunicação na Amazônia indigena. Dissertação de Mestrado. São Paulo, Universidade de São Paulo, 2000.

TURNER, T. "De cosmologia a História: resistência, adaptação e consciência social entre os Kayapó". In: VIVEIROS DE CASTRO, E. e CARNEIRO DA CUNHA, M. (org.). Amazônia: etnologia e história indígena. São Paulo, NHII/USP-Fapesp, 1993.

VELHO, G. e VIVEIROS DE CASTRO, E. "O conceito de cultura e o estudo de sociedades complexas". Artefato, ano 1, n.1, 1978.

VERSWIJVER, G. The club-fighters of the Amazon. Warfare amog the Kayapo Indians of Central Brazil. Gent, Rijkuniversteit, 1992.

VIDAL, L. Morte e vida de uma sociedade indígena brasileira. São Paulo, Hucitec, 1977.

VIVEIROS DE CASTRO, E. "Alguns aspectos da afinidade no dravidianato amazônico". In: VIVEIROS DE CASTRO, E. e CARNEIRO DA CUNHA, M. (orgs.). Amazônia: etnologia e história indigena. São Paulo, NHII/USPFapesp, 1993. 